\title{
Is CPD effective?
}

My suspicion is that the respondents in the survey were not clear

what effective meant when they provided the answers, which must bias the findings somewhat

Mike Grace m.grace.bdj@bda-dentistry.org.uk

\begin{abstract}
Ontinuing Professional Development (CPD) is continually in the news at the moment, especially now that statutory CPD is about to become a reality for the profession over the next three years. As a consequence the General Dental Council has carried out some market research among dentists who have joined the voluntary Preparatory Scheme, and the findings have just been published as a report.
\end{abstract}

The research was carried out by an independent company and 10,442 questionnaires were sent out to the profession in June 2001. Within a month 5,806 had been returned, a response rate of $56 \%$ which is quite remarkable in the time allowed. Many of the findings (see pages 639 for a summary) are very encouraging, showing overall support and confidence for CPD and placing a high value on the perceived value and benefits for both patients and the profession itself.

Digging a little deeper into the report reveals some interesting aspects, some of which are worthy of further reflection as the findings may not fully represent the reality. Most of the report consists of answers to questions related to how effective different types of both verifiable and general CPD were considered to be by the respondents, and focuses on the different methods of learning involved (such as lectures, conferences, web sites, journals and so on). For example 89\% consider Section 63 courses to be effective, $74 \%$ consider professional association meetings to be effective, $93 \%$ consider reading journals to be effective (good news for editors and authors) and so on. Areas considered to be less effective were websites offering dental education (39\%), questionnaires in journals (47\%) and vocational study days (54\%).

The problem with all these findings (in my view) is a lack of clarity over the meaning of the word 'effective'. I could not find a definition in the report, and I know for a fact that effective means different things to different people. The most common confusion is with the word 'efficient' which has a very different meaning, best explained by the glib but understandable statement: 'Being efficient means doing the thing right, being effective means doing the right thing.' Sadly in life there are a great number of people being very efficient - but they may be doing the wrong things.

Thus I have difficulty in remaining confident that the research is based on accuracy because I find so many dentists lack a clear understanding of what effective CPD means. Does it mean 'picking up a few good tips', as it is often quoted as the purpose of attending a course? Is CPD aimed simply at keeping people up-to-date? Does effective CPD have a measurable outcome that can be demonstrated if required, such as a clinical procedure or an improvement in oral health? Can effective CPD be linked to the clinical or business objectives of the practice or organisation? Or can the dentist choose any or all of the above?

We need to know before we can truly answer the question 'Is it effective?' My suspicion is that the respondents in the survey were not clear what effective meant when they provided the answers, which must bias the findings somewhat. To me the answer to the above question is also the answer to the question 'So what?' when we proudly announce that the dental profession is introducing CPD and recertification. We need clarification as a profession if we are to gain maximum value from the exercise.

Now I am not trying to discredit the survey or its findings - far from it. I am trying to ask two basic questions that I feel probe the basis of all CPD and that I do not see being addressed in this report, or in other discussions in dentistry. Why are we doing it and how do we know if it has worked? Only when we each have an answer to both these questions can we effectively answer a questionnaire on the effectiveness of the different methods of providing CPD. 